\title{
Mecanismo de Incentivo à Renovação da Mão-de-Obra no Mercado de Trabalho Face ao Sistema Previdenciário
}

\author{
Leandro Willer P. Coimbra*, Francisco de S. Ramos ${ }^{\dagger}$
}

\author{
Conteúdo: 1. Introdução; 2. A decisão de sair do mercado de trabalho: Uma breve revisão \\ da literatura; 3. Sistema de Incentivos na Decisão de Retirada do Trabalhador; \\ 4. Conclusões. \\ Palavras-chave: Sistema previdenciário; Mercado de trabalho; Incentivos. \\ Códigos JEL: D04, H23
}

Este trabalho procurou modelar a interação entre trabalhadores e firmas. Nesta perspectiva, o sistema previdenciário é visto como ferramenta de mediação dos interesses da sociedade no mercado de trabalho. Com o uso de contratos previdenciários elaborados com base no Modelo Principal-Agente, procurou-se conduzir as escolhas relacionadas à saída do mercado de trabalho, de forma a promover ganhos de pareto à sociedade através da renovação eficiente da mão-de-obra. Para tanto, fez-se necessária a adaptação das regras previdenciárias às preferências do trabalhador quanto ao trade-off trabalho-lazer, assim como, às estruturas do mercado em que estão inseridos. Contratos definidos de forma a desconsiderar os incentivos sobre o trabalhador mostraram a possibilidade de promoverem prejuízos na forma de custos sociais, de perda de competitividade e de aproveitamento ineficiente da mão-deobra.

In this work we tried to model the interaction between workers and firms. The pension system is placed as mediator between interests social in the work market. With the use of both retirement contracts based on the Principal-agent model, we tried to conduct the choice of workers to promote pareto-gains to society trough eficient renewal of labor force. For this purpose, it was necesary to adapt retirement rules to the preferences of worker's work-leisure choice and to the structure of the market they are inserted in. Contracts defined in a way that disconsider the incentives on the worker have showed the possibility of promoting damage in the form of social costs, competitiveness loss and inificient use of labor.

\footnotetext{
*Departamento de Economia, Universidade Federal de Pernambuco - UFPE E-mail: wleandru@yahoo.com.br

${ }^{\dagger}$ Departamento de Economia, Universidade Federal de Pernambuco - UFPE E-mail: ramosfs@gmail .com
} 


\section{INTRODUÇÃO}

A decisão individual do trabalhador de quando entrar e, especialmente, de quando sair do mercado de trabalho representa o principal determinante da População Economicamente Ativa - PEA. Tal decisão, resulta da influência de variáveis demográficas, econômicas, sociais e culturais, e se apresenta como objeto de atenção para o planejamento social, determinando o desempenho da economia diante da sua força produtiva.

Assim, a saída do trabalhador do mercado de trabalho marca o fim do seu período produtivo, e a partir de então, o trabalhador passa a financiar seu consumo através de uma poupança acumulada previamente. Ando e Mondigliani (1963) afirma que os ganhos durante qualquer período do ciclo de vida do trabalhador são alocados entre o consumo atual e futuro, garantindo um nível de consumo durante o período de inatividade semelhante àquele do período produtivo.

Neste contexto, a previdência, como um seguro social compulsório, faz-se necessária pela prevenção contra possíveis erros de alocação da poupança do trabalhador, o que comprometeria a sobrevivência destes indivíduos na inatividade sem "caridade social". Segundo o Ministério da Previdência e Assistência Social (MPAS, 2011), a previdência é um seguro social que visa assegurar uma renda ao contribuinte quando há perda da capacidade laboral. Para o cumprimento deste objetivo, os segurados recebem benefícios previdenciários na forma de aposentadorias e pensões, como contrapartida às contribuições compulsórias do período ativo.

Principalmente nos casos de imprevisibilidade de doença e desemprego involuntário, a não cobertura dos trabalhadores por uma rede de seguro social levaria a sociedade a arcar de forma assistencial, nos casos de erros de alocação individual, maior que a hoje feita pelo sistema previdenciário. A própria velhice considerada previsível no ciclo de vida, pode não ser bem planejada, como apresenta Izerrougene (2009, p. 33):

"Alguns indivíduos, sobretudo os mais jovens, optam pelo consumo presente, na expectativa de terem tempo no futuro para acumularem o suficiente para cobrir suas futuras necessidades."

A composição e o equilíbrio do mercado de trabalho surgem como resultados das regras que determinam as contribuições e benefícios previdenciário. Estas exercem grande influência sobre os trabalhadores sobretudo nas decisões relativas à saída do mercado. Como exemplo, Tafner (2007) cita as mudanças nas regras previdenciárias da França e da Alemanha ocorridas no início dos anos de 1970, onde o objetivo era influenciar uma saída antecipada dos trabalhadores do mercado de trabalho. Cerca de uma década depois, a idade modal de retirada já havia sido reduzida em cinco anos.

Perante regras muito benevolentes de um sistema previdenciário, há o surgimento de grandes grupos de aposentados sem o devido histórico de produção, isto é, geram as chamadas aposentadorias precoces (Conde-Ruiz e Galasso, 2003).

Por outro lado, a inexistência de um sistema de aposentadoria pode levar ao surgimento de uma mão-de-obra ativa menos produtiva e indesejada (Sala-I-Martin, 1996, Lazear, 1979).

A preocupação com a alocação dos trabalhadores no mercado de trabalho é dever básico do Estado e é apresentado na Constituição Federal no $\mathrm{Art}^{\circ} .193$ (CF/88), "A ordem social tem como base o primado do trabalho, e como objetivo o bem-estar e justiça social.". Esse dever se adapta de forma conveniente com a atuação do sistema previdenciário.

Logo, o objetivo deste trabalho é destacar os componentes microeconômicos desta influência previdenciária sobre o mercado de trabalho. Pretende-se mostrar que as regras previdenciárias possuem impactos inerentes sobre o desempenho da economia, e com isso, a formulação de regras capazes de captar as preferências dos trabalhadores possibilitaria promover ganhos sociais significativos, enquanto que desconsiderar esta influência poderia resultar em ineficiência produtiva.

O trabalho está dividido, além desta introdução, em uma breve revisão bibliográfica, que busca discutir a decisão de saída do trabalhador do mercado. Em seguida, é apresentado o modelo de incentivos, 
dividido em duas partes, o modelo formal em si, e a intuição e discussão sobre o mesmo. Por fim, são apresentadas as considerações finais.

\section{A DECISÃO DE SAIR DO MERCADO DE TRABALHO: UMA BREVE REVISÃO DA LITERA- TURA}

No Brasil, a maior probabilidade de um trabalhador se aposentar tem seu pico aos 60 e 65 anos de idade. Observa-se que a taxa de ocupação por idade entre 21 e 45 anos é acima de $80 \%$, por volta dos 45 anos, esta taxa começa a declinar, e aos 65 anos, $60 \%$ dos trabalhadores já se retiraram do mercado. Esta retirada ocorre de forma rápida neste intervalo entre 45 e 65 anos, sendo que a taxa de ocupação entre 55 e 59 anos é de 62\%; e, apenas, $47 \%$ de atividade entre 60 a 64 anos (Queiroz, 2008, Leme e Málaga, 2001).

A decisão de saída do indivíduo é determinada por uma interação entre as preferências individuais e um conjunto de incentivos que surgem principalmente nas idades mais avançadas Gustman e Steinmeier (1986). Ela é definida pela avaliação do preço, ou utilidade, do lazer em comparação à utilidade do trabalho, e é feita individualmente por cada trabalhador (Lazear, 1987).

Mitchell e Fields (1984) afirmam que as oportunidades de renda para o trabalhador de idade mais avançada são dependentes da data de retirada do mercado, das regras previdenciárias e de quem é o trabalhador. Ainda, pode-se pensar ainda que o primeiro fator é resultado dos dois outros.

Em países desenvolvidos, a decisão de saída é determinada, principalmente, pela demanda por lazer e renda e pela presença dos benefícios de seguro. Porém, nos países em desenvolvimento, aspectos como saúde, riqueza e estrutura familiar ganham maior relevância (Mete e Schultz, 2002). Para o Brasil, há um certo consenso na literatura de que fatores como nível de escolaridade, nível de renda e expectativa de vida se apresentam com uma relação positiva sobre o tempo de permanência do trabalhador na atividade (Liberato, 2003, Perez et alii, 2006, Queiroz, 2008). Perez et alii (2006) ainda apresentam que os efeitos dos fatores se diferenciam em relação ao gênero, homens e mulheres. Para as mulheres, a família representa um fator de maior importância na decisão de se aposentar do que para os homens, estes consideram os fatores econômicos mais significativos.

Com a existência de um sistema de previdência, a decisão de retirada do trabalhador passa a considerar, não apenas o salário recebido, mas também os efeitos dos benefícios e contribuições previdenciários. Em Lazear (1987) são apresentados dois influentes diretos do sistema na decisão de saída via alteração de preço trabalho/lazer:

- a redução do preço do lazer, pela possibilidade de recebimento do benefício após a retirada; e

- e a redução dos ganhos salariais, ocasionada pelas contribuições previdenciárias arrecadadas pelo sistema.

Portanto, as variações nos benefícios relacionadas à data de aposentadoria serão agregadas à decisão do trabalhador quando este se retirar da atividade. Assim, o efeito previdenciário dependerá das regras que definem a forma como os benefícios são calculados e a forma como o trabalhador enxerga a ligação entre contribuição e benefício.

Mitchell e Fields (1984) destacam as diferenças nas regras que regem diferentes planos de pensão de empresa. Alguns destes planos não apresentam nem mesmo uma tendência de incentivo seja para permanência ou saída do mercado, o que representa significativas variações na idade média de saída do trabalhador.

Gruber e Wise (1998) apresentam um índice obtido a partir das diferenças entre os valores presentes dos benefícios a se receber, caso o trabalhador adie sua aposentadoria ou não. Este índice representa os incentivos implícitos do sistema previdenciário que levam o trabalhador a se retirar do mercado. A análise do índice contraposto às taxas de capacidade de mão-de-obra não usada mostrou claramente 
uma relação positiva em 11 países industrializados, dentre indivíduos com idades entre 55 e 65 anos Gruber e Wise (1998). ${ }^{1}$

Em outro estudo focado no mercado de oferta de mão-de-obra brasileira, Liberato (2003) discorre sobre os determinantes que levam o trabalhador permanecer ou não no mercado após a aposentadoria. Com base nos dados da Pesquisa Nacional por Amostra de Domicílio - PNAD, para o período de 1981 a 2001, constatou-se que menores benefícios previdenciários levam os trabalhadores a permanecerem mais no mercado. Esta conclusão ainda é estendida para mudanças estruturais, como a redução do teto da previdência social, que tenderia a reduzir o benefício de muitos trabalhadores e, consequentemente, a elevar o nível de participação no mercado.

Ainda há que se considerar que as habilidades humanas físicas e mentais depreciam com o passar do tempo, atingindo seu auge por volta dos 45 anos. Após isso ela declina, com evidências de que a produtividade aos 65 anos é menor que 1/3 em relação ao período de pico (Kotlikoff e Gokhale (1992) apud Sala-I-Martin (1996)).

Espera-se que o valor presente dos ganhos na utilidade de permanecer no mercado de trabalho oferecido pelos sistemas previdenciários apresente a forma de $u$ invertido (Lazear, 1987). Este fato leva a um período de crescimento até um pico, o que representa um incentivo a permanência no mercado, e a partir de então uma queda, período que marca o início dos incentivos a retirar-se, seguindo o comportamento da depreciação da produtividade.

Sala-I-Martin (1996) surge com uma abordagem diferente frente aos estudos do sistema previdenciário. Seu foco foge à discussão a respeito dos crescentes déficits e mesmo da função básica de formação de poupança para a inatividade (pontos bastantes discutidos na literatura). E busca justificar a existência do sistema previdenciário frente às questões de difícil entendimento, como por exemplo, por que nos EUA o ganho sobre capital não interfere nos ganhos previdenciário, porém a remuneração do trabalho pode levar à perda total destes? Tal questionamento foge às teorias que justificam a presença da previdência social motivada por governos paternalistas ou pela inexistência de um mercado financeiro apropriado para gerir a poupança para a inatividade dos trabalhadores.

Para Sala-I-Martin (1996), as transferências em forma de benefícios são uma forma de "comprar" a saída do trabalhador idoso, baseada na perda de produtividade ao longo dos anos. Sua principal contribuição está na teoria de que trabalhadores de baixa produtividade geram externalidades negativas sobre toda a economia. Assim, é apresentada uma função de produção em que onde a produtividade das pessoas não depende somente das suas próprias habilidades, mas também, daquelas que as cercam: "If workers are in contact with high quality people, their own productivity is larger" (Sala-I-Martin, 1996, p. 16). Como a firma poderá contratar um trabalhador indesejável para a sociedade, mas ainda relevante para ela, haverá um ganho social que justifica a atuação do governo.

Com o mesmo objetivo de explicar a existência de um sistema previdenciário social, Bhattacharya et alii (2004) fizeram uso de um modelo de procura no mercado de trabalho, ${ }^{2}$ onde apresentam uma externalidade do trabalhador idoso sobre os objetivos dos desempregados. Com base nos custos de procura do trabalhador desempregado e no menor custo oportunidade dos trabalhadores mais jovens, baseado no trade-off entre trabalho e lazer, o sistema previdenciário surge promovendo um ganho no bem estar social. Contudo, a depender dos parâmetros, a existência do sistema previdenciário pode não ser necessária. Além do que, para casos extremos onde a visão social seria mais necessária, o modelo apresenta menores necessidades de intervenções que aquelas observadas em muitos países na realidade.

Os trabalhos citados de Sala-I-Martin (1996), Bhattacharya et alii (2004), assim como outros, como Cooley (1999), Tabellini (2000) seguem uma linha de pesquisa que procura entender as diversas funções do sistema previdenciário que justificam sua existência, uma teoria positiva da previdência social. As

\footnotetext{
${ }^{1}$ Os autores ressaltam que apesar de uma evidente relação, alguns países apresentaram uma estrutura previdenciária construída com base na estrutura da população, o que pode indicar a existência de dupla causalidade para alguns casos.

${ }^{2}$ Model Labor Market Search
} 
seções a seguir vêm adicionar a esta discussão, a atuação do sistema previdenciário sob a ótica de uma ferramenta de política social para o mercado de trabalho e a importância de considerar os determinantes individuais da saída do trabalhador, que repercutem sobre a diversidade da sociedade.

\section{SISTEMA DE INCENTIVOS NA DECISÃO DE RETIRADA DO TRABALHADOR}

Neste capítulo é desenvolvido o modelo da retirada do trabalhador, através dos fundamentos do modelo Principal-Agente, partindo-se do pressuposto da existência de um conflito entre os interesses individuais e sociais inseridos no mercado de trabalho. O sistema previdenciário surge como um mediador, procurando promover um maior bem estar social, para isso define-se o governo (principal) como aquele que declara o contrato previdenciário que deverá conter os incentivos adequados ao agente, neste caso, o trabalhador.

Ao entrar no mercado de trabalho, o trabalhador estabelece com base em fatores exógenos o tempo em que permanecerá ativo, ou seja, o trabalhador determina uma data natural para sair do mercado de trabalho, ou seja, se aposentar.

Assim, o sistema previdenciário surge com o objetivo inicial e fundamental de instituir um contrato compulsório que assegure o financiamento do período improdutivo deste trabalhador, marcado por sua decisão natural de saída. Para tanto, o contrato determina a cobrança de contribuições e tem como contrapartida o pagamento de benefícios ao trabalhador, ambos definidos de forma a não gerar déficits para o sistema.

Com a proximidade da data de saída natural, o agente é, enfim, contraposto à decisão de finalizar o contrato previdenciário ou permanecer no mercado por mais tempo. Aceitar o fim do contrato implica em se retirar e fazer uso da poupança previdenciária. O jogo acontece a partir do trade-off trabalho-lazer, sendo mais custoso ao trabalhador permanecer no mercado quanto mais distante for a data efetiva de saída para com a data natural anteriormente prevista. Por outro lado, na tentativa de comprar a decisão de saída do trabalhador, o governo atuará sobre as regras que definem os benefícios previdenciários de acordo com os interesses sociais no mercado de trabalho. A evolução deste jogo pode ser observada com base na linha do tempo representada na figura 1 .

Figura 1: Tempo do Jogo

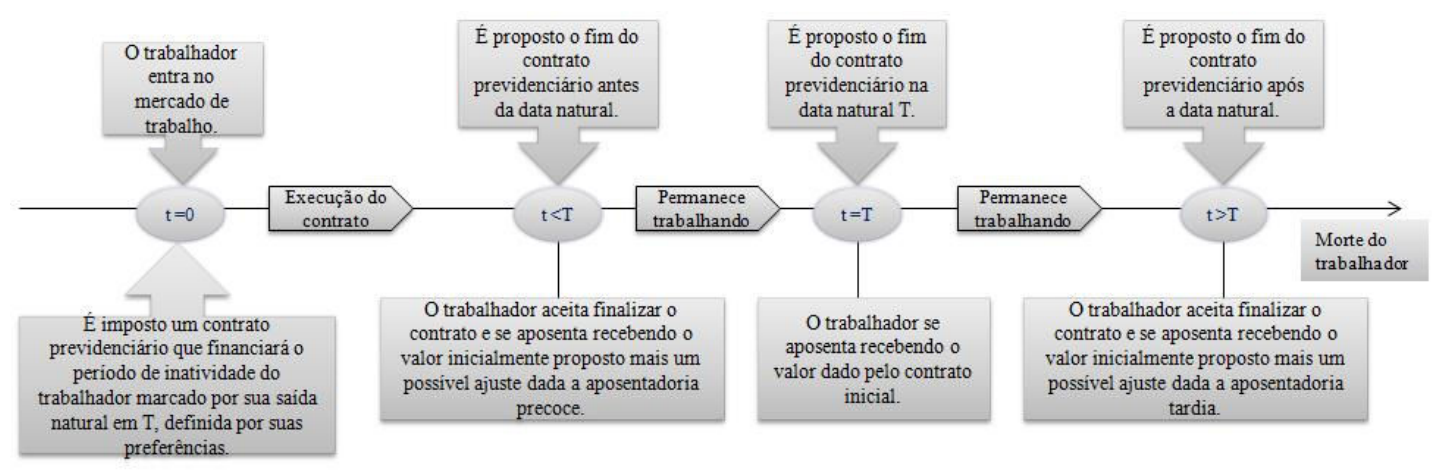

Esta modelagem fará uso da base teórica fornecida pelos modelos de ciclo de vida que inserem a relação existente dos benefícios previdenciários e a saída do mercado de trabalho, como em Lazear (1979, 1987), Gustman e Steinmeier (1986), e Queiroz (2008), dentre outros, e tem como base para os questionamentos a teoria positiva da previdência social. Além disso, faz uso dos fundamentos dos modelos de Principal-Agente inseridos na teoria dos incentivos. 
Depois, será apresentado o modelo formal iniciado pela descrição da tomada de decisão dos trabalhadores quanto à decisão de saída do mercado de trabalho. Segue-se com a introdução do sistema previdenciário baseado em um sistema tributário passivo, no qual o governo se foca na manutenção da estabilidade financeira. Então, é apresentado um sistema tributário ativo, no qual o governo busca a eficiência alocativa no mercado de trabalho baseado nas externalidades geradas pelo sistema previdenciário. Por fim, é feita uma discussão com base nos pontos-chaves do modelo.

\subsection{O Modelo}

\subsubsection{A decisão do trabalhador}

Em contrapartida aos ganhos salariais, o tempo gasto no trabalho implica em menor tempo para atividades outras, como viagens, tempo com a família, hobbies e mesmo cuidados com a saúde. Ao se definir lazer como atividades de não-trabalho, é possível dizer que existe uma desutilidade gerada devido a este trade-off entre trabalho e lazer.

A desutilidade, representada de forma acumulada por $\theta(t, d)$, é função do tempo. Este pode ser entendido como a idade do trabalhador, tempo de permanência no mercado de trabalho ou mesmo uma combinação de ambos. Além disso, é determinada, também, por uma disposição a se aposentar definida individualmente por características exógenas, como, condições de trabalho, qualidade de vida, estrutura familiar, religiosa, institucional, dentre outras influências sobre as preferências do trabalhador quanto ao trade-off enunciado. ${ }^{3}$

Como a desutilidade de permanecer no mercado de trabalho é dada de forma acumulada com base na disposição a se aposentar, o tempo e a disposição possuem relação positiva com a primeira. Assim como também, supõe-se que a cada unidade de tempo na atividade, maior é a disposição a se aposentar e maior é seu incremento marginal. Mais formalmente, as pressuposições acima podem ser descritas, respectivamente, como:

$$
\begin{aligned}
\theta_{(t)}^{\prime}(d, t) & >0 \\
\theta_{(t t)}^{\prime \prime}(d, t) & >0 \\
\theta_{(d)}^{\prime}(d, t) & >0 \\
\theta_{(t d)}^{\prime \prime}(d, t) & >0
\end{aligned}
$$

Supõe-se que o trabalhador despende um tempo ao lazer constante durante seu período produtivo, ocupando-se totalmente com este ao se retirar do mercado (Lazear, 1987). Portanto, a maximização do lazer ocorre com a determinação desta data de saída. Em contrapartida, esta decisão marca o fim do recebimento da remuneração pelo trabalho e, consequentemente, também determina a renda ao longo da vida.

A função utilidade do trabalhador pode ser descrita como:

$$
U(c(t), \Delta c(t, M), \theta(d, t))
$$

\footnotetext{
${ }^{3}$ Em Bhattacharya et alii (2004) é apresentado a disposição a se aposentar de forma semelhante, sendo que a denominação de desutilidade acumulada, aqui utilizada, foi definida como uma função de distribuição acumulada do custo do trabalho.
} 
s. a:

$c(t)=w(t)-s(t)$

$\Delta c(t, M)=s(t)$

onde:

$c(t)$ é o valor presente do consumo até este tempo $t$;

$\Delta c(t, M)$ é a diferença do valor presente do consumo entre o tempo $t$ e a morte em $M$;

$\theta(d, t)$ é a desutilidade acumulada do trabalho até $t$, em função da disposição a se retirar, $d$;

$w(t)$ é o valor presente do salário até o tempo $t$;

$s(t)$ é o valor presente da poupança acumulada até o tempo $t$.

Portanto, considerando $t$ na função, como o tempo que marca o fim da vida produtiva do trabalhador, tem-se que o trabalhador possui uma função utilidade definida pelos ganhos salariais e pela desutilidade do trabalho, o que representa seus ganhos e perdas acumuladas no período de atividade laboral. Ressalta-se que os ganhos salariais acumulados no período ativo, além de propiciar o consumo na atividade, também devem propiciar a poupança para o financiamento do período improdutivo do ciclo de vida. ${ }^{4}$

A decisão do trabalhador quanto a data de saída ótima, ou natural $(T)$ ocorre quando houver igualdade entre os ganhos e perdas marginais de se permanecer no mercado de trabalho. Seja uma função de utilidade do trabalhador dada em sua forma linear: $U(c, \Delta c(t, M), \theta)=c(t)+\Delta c(t, M)-\theta(d, t)=$ $[w(t)-s(t)]+s(t)-\theta(d, t)=U(w, \theta)$

Logo, a data de saída natural é definida por:

$$
\begin{array}{r}
\left(\frac{\partial U(w, \theta)}{\partial w}\right)\left(\frac{\partial w}{\partial t}\right)+ \\
\left(\frac{\partial U(w, \theta)}{\partial \theta}\right)\left(\frac{\partial \theta}{\partial t}\right)=0 \\
\rightarrow \frac{\partial w(T)}{\partial t}=\frac{\partial \theta(d, T)}{\partial t}
\end{array}
$$

Nas seguintes seções, considera-se uma população com trabalhadores idênticos que se distinguem apenas por suas disposições a sair do mercado. Há dois tipos de trabalhadores: com alta disposição a se aposentar, $d_{A}$, isto é, possui alta desutilidade de permanência no mercado e, consequentemente, alto apreço pelo lazer; e, trabalhadores com baixa disposição a se aposentar, $d_{B} \cdot{ }^{5}$ A probabilidade de um trabalhador possuir alta ou baixa disposição a se aposentar é, respectivamente, dada por $\lambda$ e $(1-\lambda){ }^{6}$

Como ambos os trabalhadores recebem salários iguais, possuindo ambos as mesmas características produtivas, as decisões quanto à data de saída do mercado se diferenciam pela desutilidade que cada um enfrenta por estar na atividade. Observa-se que $d_{A}>d_{B} \Rightarrow \theta\left(d_{A}, t\right)>\theta\left(d_{B}, t\right) \Rightarrow T_{B}>T_{A}$, ou seja, o trabalhador com alta disposição a se retirar tende a sair primeiro que o trabalhador com baixa disposição.

\footnotetext{
${ }^{4}$ Desconsidera-se a remuneração do capital.

${ }^{5}$ Esta desutilidade não deve ser confundida com um custo de produção, dado que não está ligada diretamente ao nível de produtividade do trabalhador, mas ao fato de estar trabalhando.

${ }^{6}$ A investigação sobre $\lambda$ é dada com base nas distribuições daqueles determinantes da saida dos trabalhadores na população, citados na Seção 2.
} 


\subsubsection{0 sistema previdenciário como um seguro social}

O sistema previdenciário surge, em grande parte da literatura, devido a imperfeição do mercado financeiro e da miopia dos trabalhadores quanto à formulação da poupança de longuíssimo prazo para financiamento do período inativo. ${ }^{7}$ Consequentemente, o governo impõe ao trabalhador um contrato onde a previdência arrecada contribuições compulsórias que serão revertidas em benefícios previdenciários no futuro.

As contribuições previdenciárias, representada de forma acumulada no tempo por $p(t)$, recaem sobre trabalhador e empresa, ${ }^{8}$ sendo $p_{\alpha}(t)$ a parcela da contribuição acumulada que recai sobre os trabalhadores.

O benefício previdenciário é pago ao trabalhador após sua decisão de saída do mercado e é representado de forma acumulada no tempo por $b(t)$. Por fim, o saldo nas contas previdenciárias é dado por:

$$
p(t)-b(t)
$$

Como anteriormente, o trabalhador define sua saída de acordo com os ganhos e perdas marginais de sua permanência no mercado, contudo, a atuação da previdência passa a compor sua função utilidade, devido aos ganhos com os benefícios previdenciários e as perdas com o pagamento das arrecadações. A definição do contrato previdenciário passa a ser um determinante nas decisões do trabalhador.

A princípio, é desconsiderada qualquer externalidade do sistema previdenciário sobre a sociedade, ${ }^{9}$ sendo que o único benefício que este sistema traz é garantir a poupança da inatividade para os trabalhadores. A busca do governo pelo bem estar social é, então, representada pela busca do equilíbrio fiscal, pois não há um ganho considerado que justifique outro resultado, e qualquer superávit ou déficit seria injusto para a sociedade ou para o contribuinte previdenciário.

Com a intenção de não intervir sobre as decisões dos agentes, o governo visará elaborar contratos que sigam o objetivo primário de um sistema previdenciário, que é garantir a formação da poupança para a inatividade, respeitando as escolhas naturais dos agentes e buscando o equilíbrio fiscal entre arrecadação e benefício. Para uma sociedade com população ativa de tamanho $N$, na qual a distribuição de indivíduos no mercado de trabalho com alta e baixa disposição a se aposentar é dada ,respectivamente, por $\lambda$ e $1-\lambda$, o objetivo do governo referente à busca pelo equilíbrio financeiro é representado por:

$$
\sum^{N} \lambda\left\{p\left(T_{A}\right)-b\left(T_{A}\right)\right\}+(1-\lambda)\left\{p\left(T_{B}\right)-b\left(T_{B}\right)\right\}=0
$$

Ou seja, a manutenção de um saldo previdenciário não-positivo e não-negativo deve considerar as proporções de cada tipo de trabalhador na população. Além disso, apesar do governo determinar o valor das contribuições e benefícios, o tempo de retirada na função objetivo é dado pela escolha natural do trabalhador, $T_{A}$ e $T_{B}$, ou seja, o sistema previdenciário não interfere nesta decisão.

\footnotetext{
${ }^{7}$ Segundo o Ministério da Previdência e Assistência Social (MPAS, 2011), a previdência é um seguro social que visa assegurar uma renda ao contribuinte quando há perda da capacidade.

${ }^{8}$ Esta divisão de responsabilidades é atribuída segundo Art.195 da CF/88. Além disso, em Lazear (1979), há um interesse das empresas na existência de um sistema previdenciário que institua uma aposentadoria compulsória, fato que justificaria a participação destas no custeamento do sistema. Não é do escopo deste trabalho a disussão a respeito dos motivos da divisão deste custeamento entre empresas e trabalhadores. Ressalta-se, contudo que existe certa rigidez na razão da contribuição previdenciária entre empresas e trabalhadores no Regime Geral de Previdência Social brasileiro e a primeira corresponde a cerca de duas vezes a contribuição do trabalhador assalariado.

${ }^{9}$ Hipótese que será quebrada na seção seguinte.
} 
Baseado na crença de que o contrato previdenciário garantirá sua decisão de saída, assim como sua sobrevivência após o período ativo, o trabalhador passa a ter as contribuições previdenciárias como única forma de poupança. ${ }^{10}$ Esta simplificação visa dar foco aos efeitos do benefício previdenciário.

Mantendo a forma linear da utilidade do trabalhador, define-se uma restrição de existência da previdência que garanta uma utilidade mínima a este trabalhador através da suavização do seu consumo ao longo da vida. ${ }^{11}$

$$
\begin{array}{r}
\left(w\left(T_{A}\right)-p_{\alpha}\left(T_{A}\right)\right)-\theta\left(d_{A}, T_{A}\right)+b\left(T_{A}\right) \geq \bar{c}-\theta\left(d_{A}, T_{A}\right) \\
\left(w\left(T_{B}\right)-p_{\alpha}\left(T_{B}\right)\right)-\theta\left(d_{B}, T_{B}\right)+b\left(T_{B}\right) \geq \bar{c}-\theta\left(d_{B}, T_{B}\right)
\end{array}
$$

O lado esquerdo da equação apresenta a utilidade do trabalhador ao se contabilizar os ganhos dos benefícios, $b(t)$, e a perda pelo pagamento das contribuições, $p(t)$. No lado direito, é representada a utilidade mínima a ser garantida ao longo da vida. Observa-se que nesta última, considera-se que o trabalhador deva cumprir uma contribuição social na forma de trabalho, representada pela desutilidade de permanência no mercado, $\theta(d, t)$. O termo $\bar{c}$ revela o valor presente do consumo mínimo que deve ser garantido ao trabalhador, contabilizando o período ativo e inativo, até a data de sua morte. Este termo de consumo mínimo é dado pela visão do governo quanto ao planejamento de longo prazo, ou seja, este termo determina a suavização do consumo imposta pelo contrato previdenciário, dada a incapacidade do trabalhador para tal planejamento. ${ }^{12}$

Baseado na equação 6 , determina-se o menor benefício capaz de garantir a utilidade mínima ao trabalhador ao longo da vida em função da contribuição previdenciária.

$$
\begin{aligned}
& b\left(T_{A}\right)=\bar{c}-\left(w\left(T_{A}\right)-p_{\alpha}\left(T_{A}\right)\right) \\
& b\left(T_{B}\right)=\bar{c}-\left(w\left(T_{B}\right)-p_{\alpha}\left(T_{B}\right)\right)
\end{aligned}
$$

Como apresentado anteriormente, sendo $d_{A}>d_{B}$ ocorre que $T_{B}>T_{A}$, ou seja, o período de inatividade e, consequentemente, a necessidade de financiamento deste pelos trabalhadores com baixa disposição a se aposentar é menor que para trabalhadores com alta disposição. Ao considerar a mesma alíquota de contribuição por unidade de tempo para todos os tipos de trabalhadores ${ }^{13}$ é possível mostrar que $b\left(T_{B}\right)>b\left(T_{A}\right)$ pois:

$$
\begin{aligned}
b\left(T_{B}\right) & =\bar{c}-\left(w\left(T_{B}\right)-p_{\alpha}\left(T_{B}\right)\right) \\
& =\underbrace{\bar{c}-\left(w\left(T_{A}\right)-p_{\alpha}\left(T_{A}\right)\right)}_{=b\left(T_{A}\right)}-\underbrace{\left(\Delta w\left(T_{B}, T_{A}\right)-\Delta p_{\alpha}\left(T_{B}, T_{A}\right)\right)}_{=\left(w\left(T_{B}\right)-p_{\alpha}\left(T_{B}\right)\right)-\left(w\left(T_{A}\right)-p_{\alpha}\left(T_{A}\right)\right)}
\end{aligned}
$$

\footnotetext{
${ }^{10}$ Sala-I-Martin (1996) apresenta uma série de trabalhos que defendem esta dependência para com o sistema que interfere em sua decisão de poupar. Cita, ainda os trabalhos de Browning (1979), Vergara (1990) e Kotlikoff (1987) que mostram que indivíduos pobres tendem a não poupar quando jovens quando sabem que existe alguém cuidando disso por eles. Ferreira (2007) mostra que de 14 trabalhos, entre 1979 e 1997, que foram analizados, 10 demonstraram correlação negativa entre riqueza privada e riqueza previdenciária.

${ }^{11}$ Esta restrição, dentro da teoria do Pincipal-Agente, é conhecida como restrição de entrada do agente . A alteração na denominação é devido a compulsoriedade do contrato sobre o trabalhador. O respeito a esta restrição garante seu papel fundamental, justificando assim sua existência.

${ }^{12}$ A determinação desta variável deverá considerar, além do tempo de vida do trabalhador, pesos diferentes para o consumo na atividade e inatividade. No presente trabalho será considerado como variável exógena.

${ }^{13}$ Com base na proposta de uma análise positiva do sistema previdenciário para com os efeitos dos benefícios, não será dispendido tempo na análise para uma possibilidade de definir níveis de contribuição diferentes para tipos diferentes. Tal situação levaria a uma contribuição menor para indivíduos com baixa disposição a se retirar enquanto a arrecadação total e média, que nos é mais interessante, seria a mesma. Portanto, opta-se, mais uma vez, em não discutir a partilha de responsabilidades dentre os financiadores do sistema previdenciário.
} 
O termo $\left(\Delta w\left(T_{B}, T_{A}\right)-\Delta p_{\alpha}\left(T_{B}, T_{A}\right)\right)$ representa esta menor necessidade de financiamento do período improdutivo para o trabalhador com disposição baixa a sair.

A equação 5, por sua vez, determina a arrecadação média por trabalhador necessária para promover o equilíbrio financeiro do sistema:

$$
p\left(T_{A}\right)+(1-\alpha) \Delta p\left(T_{B}, T_{A}\right)=\bar{c}-\left\{w\left(T_{A}\right)-p_{\alpha}\left(T_{A}\right)\right\}-(1-\lambda)\left\{\Delta w\left(T_{B}, T_{A}\right)-\Delta p_{\alpha}\left(T_{B}, T_{A}\right)\right\}
$$

Através da Equação 9 é possível determinar uma contribuição $p^{*}$ por unidade de tempo e, consequentemente, um $p_{\alpha}^{*}$ capaz de preservar o equilíbrio nas contas previdenciárias e promover a suavização do consumo no ciclo de vida.

A contribuição até o período $T_{A}$ é feita por toda a população, havendo uma complemetariedade por parte daqueles que permanecerem no mercado após esta data, $\Delta p\left(T_{B}, T_{A}\right)$. Além de contribuirem com uma porção maior do financiamento, esta mesma parcela da população se apresenta mais independente com relação ao financiamento do consumo ao longo da vida. Permanecer no mercado por mais tempo, implica em menor tempo de inatividade e menor necessidade de financiamento pelo sistema previdenciários, ${ }^{14}\left\{\Delta w\left(T_{B}, T_{A}\right)-\Delta p_{\alpha}\left(T_{B}, T_{A}\right)\right\}$, reduzindo, consequentemente, a arrecadação média sobre trabalhadores.

Em suma, em termos de financiamento do sistema previdenciário, o percentual de participação entre os dois tipos de trabalhadores existentes na economia tendem a ser relevantes para com o valor da contribuição previdenciária. Quanto maior a parcela da sociedade com baixa disposição a sair do mercado, menor a necessidade de intervenção do sistema previdenciário, dado o menor período de inatividade da população. Contabiliza-se também uma transferência intrageracional dos trabalhadores com disposição $d_{B}$ para com o trabalhadores com disposição $d_{A}$ que, apesar de contribuir efetivamente mais, utiliza menos desssa arrecadação. Tais resultados podem ser melhor observados pela equação 10, abaixo que apresenta os beneficios escritos em função da arrecadação média da população:

$$
\begin{aligned}
& b^{*}\left(T_{A}\right)=p\left(T_{A}\right)+(1-\lambda)\left\{\Delta p\left(T_{B}, T_{A}\right)+\Delta c\left(T_{B}, T_{A}\right)\right\} \\
& b^{*}\left(T_{B}\right)=p\left(T_{A}\right)+(1-\lambda)\left\{\Delta p\left(T_{B}, T_{A}\right)\right\}-\lambda\left\{\Delta c\left(T_{B}, T_{A}\right)\right\}
\end{aligned}
$$

Proposição 1. O benefício dos trabalhadores com baixa disposição a se aposentar é menor que o beneficio com alta disposição, no caso em que não haja assimetria de informação quanto aos tipos dos agentes.

Isto ocorre pois, o trabalhador que opta por sair mais tarde, possui maior independência no financiamento do seu consumo. Observa-se ainda que os beneficios pagos aos trabalhadores que saem mais precocemente apresentará parte de seu financiamento feito pelo restante dos trabalhadores que passam mais tempo contribuindo e menos tempo dependentes do financiamento previdenciário. Esta situação, permite à previdência fazer uso de uma distribuição intrageracional, em que o trabalhador do tipo $d_{B}$ ajuda a financiar o trabalhador de tipo $d_{A}$.

Baseado na racionalidade dos trabalhadores e na diferença dos benefícios acumulados, onde $b\left(T_{A}\right)$ se apresenta maior que $b\left(T_{B}\right)$, a quebra da hipótese de informação perfeita no momento de finalizar o contrato previdenciário pode promover resultados, por hora, indesejados. O contrato elaborado até aqui pode estabelecer uma vantagem para um trabalhador que minta a respeito de suas preferências, neste caso, especificamente para o tipo $d_{B}$. Ou seja, os trabalhadores podem ser levados a se retirarem em uma data diferente de sua decisão natural, dada a intervenção do sistema previdenciário. Com a intenção de preservar a neutralidade do sistema, acrescenta-se ao problema uma restrição de compatibilidade de incentivos. Esta deve garantir que os trabalhadores revelem quem são, e se retirem de acordo com suas escolhas iniciais. O problema da escolha da contribuição por unidade de tempo $p$ e os

\footnotetext{
${ }^{14}$ Supondo que ambos tenham a mesma data de morte.
} 
beneficios pagos nas devidas datas de saída $b\left(T_{A}\right)$ e $b\left(T_{B}\right)$ passam a:

$$
\sum^{N} \lambda\left\{p\left(T_{A}\right)-b\left(T_{A}\right)\right\}+(1-\lambda)\left\{p\left(T_{B}\right)-b\left(T_{B}\right)\right\}=0
$$

sendo que:

$$
\begin{aligned}
\left(w\left(T_{A}\right)-p_{\alpha}\left(T_{A}\right)\right)-\theta\left(d_{A}, T_{A}\right)+b\left(T_{A}\right) & \geq \bar{c}-\theta\left(d_{A}, T_{A}\right) \\
\left(w\left(T_{B}\right)-p_{\alpha}\left(T_{B}\right)\right)-\theta\left(d_{B}, T_{B}\right)+b\left(T_{B}\right) & \geq \bar{c}-\theta\left(d_{B}, T_{B}\right) \\
\left(w\left(T_{A}\right)-p_{\alpha}\left(T_{A}\right)\right)-\theta\left(d_{A}, T_{A}\right)+b\left(T_{A}\right) & \geq\left(w\left(T_{B}\right)-p_{\alpha}\left(T_{B}\right)\right)-\theta\left(d_{A}, T_{B}\right)+b\left(T_{B}\right) \\
\left(w\left(T_{B}\right)-p_{\alpha}\left(T_{B}\right)\right)-\theta\left(d_{B}, T_{B}\right)+b\left(T_{B}\right) & \geq\left(w\left(T_{A}\right)-p_{\alpha}\left(T_{A}\right)\right)-\theta\left(d_{B}, T_{A}\right)+b\left(T_{A}\right)
\end{aligned}
$$

O lado esquerdo destas duas últimas restrições apresenta a utilidade do trabalhador ao sair do mercado de trabalho em sua data natural de se aposentar. A restrição garante que seja mais vantajoso manter esta data que optar por sair de acordo com a data de um outro contrato (lado direito da equação). O novo menu de contratos é dado com a garantia de que cada trabalhador se retire em seu devido tempo.

Com base nas pressuposições sobre $\theta(d, t)$, definidas pelas equações 2 , permite-se dizer que em $\Delta \theta\left(d_{B}, T_{B}, T_{A}\right)<\Delta \theta\left(d_{A}, T_{B}, T_{A}\right)$ os benefícios previdenciários são dados por:

$$
\begin{aligned}
b\left(T_{A}\right) & =\bar{c}-\left(w\left(T_{A}\right)-p_{\alpha}\left(T_{A}\right)\right) \\
b\left(T_{B}\right) & =\bar{c}-\left(w\left(T_{B}\right)-p_{\alpha}\left(T_{B}\right)\right)+\left(\Delta \theta\left(d_{B}, T_{B}, T_{A}\right)\right) \\
& =\bar{c}-\left(w\left(T_{A}\right)-p_{\alpha}\left(T_{A}\right)\right)+\underbrace{\left(\Delta \theta\left(d_{B}, T_{B}, T_{A}\right)\right)-\left(\Delta w\left(T_{B}, T_{A}\right)-\Delta p_{\alpha}\left(T_{B}, T_{A}\right)\right)}_{<0}
\end{aligned}
$$

Obtém-se, desta forma, a arrecadação previdenciária média por trabalhador para manutenção do equilíbrio financeiro do sistema:

$$
\begin{gathered}
p\left(T_{A}\right)+(1-\lambda) \Delta p\left(T_{B}, T_{A}\right)=\bar{c}-\left\{w\left(T_{A}\right)-p_{\alpha}\left(T_{A}\right)\right\}-(1-\lambda) \\
\left\{\left(\Delta w\left(T_{B}, T_{A}\right)-\Delta p_{\alpha}\left(T_{B}, T_{A}\right)\right)-\Delta \theta\left(d_{B}, T_{B}, T_{A}\right)\right\}
\end{gathered}
$$

A arrecadação, apresentada na equação 14 sob a hipótese de assimetria de informação, determina uma contribuição média por trabalhador em cada unidade de tempo maior que aquela apresentada pela equação 7 , ou seja, $p^{* *}>p^{*}$. O maior volume de arrecadação é devido ao necessário pagamento do prêmio pela informação não compartilhada sobre as preferências dos trabalhadores com disposição $d_{B}$, $\Delta \theta\left(d_{B}, T_{B}, T_{A}\right)$.

Como anteriormente, o benefício $b\left(T_{A}\right)$ é financiado pela maior contribuição e menor necessidade de financiamento do consumo do trabalhador de tipo $d_{B}, \Delta p\left(T_{B}, T_{A}\right)$ e $\Delta c\left(T_{B}, T_{A}\right)$, respectivamente. Porém, as restrições de compatibilidade de incentivo exigem que os custos de resultados diferentes sejam devidamente remunerados, pois desta forma, elimina-se o interesse do agente em ocultar suas preferências e optar por contratos inadequados ao interesse do principal (o governo). 0 custo de permanência do trabalhador no mercado após o tempo $T_{A}$ é determinado por $\Delta \theta\left(d_{B}, T_{B}, T_{A}\right)$, consequentemente, isto terá que se refletir nos beneficios a se receber em $T_{B}$ e seu financiamento eleva o nível de arrecadação médio por trabalhador. Este aumento promove uma contribuição média por trabalhador maior, em cada unidade de tempo, e é repassado ao trabalhador $d_{B}$ na forma de benefício. Consequentemente, $b\left(T_{B}\right)$ será em parte financiado pelo trabalhador com disposição $d_{A}$.

Proposição 2. A elaboração de contratos eficientes respeitando as decisões dos trabalhadores e sem o conhecimento das preferências individuais resulta em maiores custos na manutenção do sistema que objetiva: garantir a formação da poupança para a inatividade; respeitar as escolhas naturais dos agentes; e buscar o equilíbrio fiscal entre arrecadação e benefício. 
Estes são relativos a maior diferença temporal entre as datas de saídas dos trabalhadores e a evolução da função de desutilidade neste intervalo. Ou seja, quanto maiores forem as diversidades entre as preferências dos trabalhadores em relação ao trabalho, maiores são os custos implicados na manutenção deste sistema.

É possível observar que o desempenho da previdência na adaptação das regras às características da sociedade, mesmo não sendo de sua pretensão, acaba por influenciar o desempenho da economia dado possíveis aumentos de custo da mão-de-obra ou mudança na oferta desta. Parte-se, em seguida, para a análise de perdas ou ganhos determinados ao mercado de trabalho quando a previdência toma consciência de sua influência sobre o trabalhador.

\subsubsection{As externalidades do sistema previdenciário sobre o mercado de trabalho}

Até este ponto, o jogo anunciado na subseção 3.1 (Figura 1) focou primeiramente na decisão do trabalhador quanto a data de saída natural, baseado em sua disposição a sair do mercado e os salários (subseção 3.1.1). Em seguida, determinou-se a atuação da previdência como garantidora da poupança para financiamento do período inativo do trabalhador, respeitando sua decisão inicial (subseção 3.1.2). Seguindo a linha do tempo deste jogo, ao se aproximar o fim do contrato, ou seja, ao se aproximar a data de retirada natural dos trabalhadores, o governo passa a visar uma atuação mais ativa, onde está buscando coordenar as externalidades do sistema previdenciário sobre o mercado de trabalho.

Ao longo do ciclo de vida, o trabalhador passa por diferentes níveis de produtividade. Inicia a vida ativa com uma função crescente no tempo, tem o período de maior acúmulo de capital humano, vindo, no futuro, a declinar e convergir para um nível de produtividade não mais interessante ao mercado de trabalho, marcando o fim do período ativo do trabalhador pela visão das firmas.

Segundo Lazear (1979) os salários podem não acompanhar estas tendências de produtividade, estes seriam maiores nos períodos mais avançados do ciclo de vida e menores no início. Este comportamento é uma tentativa de estimular o trabalhador, ao longo do tempo, a não se demitir antes do previsto pelo empregador. Desta forma, os ganhos sobre o trabalhador, determinados pela diferença entre a produtividade e o salário, tenderiam a ser menores em função do tempo. Ao considerar um salário fixo ao longo da vida, contraposto ao comportamento da produtividade, este preserva e enfatiza esta variação dos ganhos das empresas sobre os trabalhadores ao longo do ciclo de vida.

Considera-se, ainda, a existência de um contingente de trabalhadores reservas, candidatos a assumir o lugar daqueles que se encontram atualmente no mercado. Apesar de se considerar ganhos não decrescentes no tempo sobre um trabalhador (para salários não maiores que a produtividade), a permanência em demasia de um trabalhador pode implicar em prejuízos à eficiência, quando comparadas as possibilidades de ganho com uma substituição.

Assume-se que o trabalhador não considera, em seu processo de decisão de saída do mercado de trabalho, a possibilidade de gerar ineficiência produtiva para a sociedade. As firmas, por outro lado, possuem informação sobre as produtividades dos trabalhadores que permitiriam uma decisão mais socialmente eficiente, contudo, existem externalidades e falhas de mercado quanto à renovação da mão de obra. Segundo Sala-I-Martin (1996), uma mão de obra com produtividade baixa no mercado gera uma externalidade negativa, pois acaba por desestimular outros trabalhadores. Em Bhattacharya et alii (2004), os custos de procura por emprego são apresentados como efeitos externos à decisão de aposentadoria realizada conjuntamente pelas empresas e trabalhadores veteranos, gerando ineficiência alocativa. Já suposição em Lazear (1979) é que o sistema previdenciário elimina os custos de demissão, que podem ser altos, principalmente sobre trabalhadores com extenso histórico em uma empresa. Assim, poderia haver ainda uma aversão ao risco das empresas por trabalhadores novatos que levaria ao adiamento na retirada de trabalhadores. Em Leme e Málaga (2001) é apresentado os efeitos da previdência sobre o nível de capital humano baseado em um trade-off entre trabalho e estudo, em que retiradas muito precoces levariam a maior procura de trabalhadores, e portanto, menos tempo para se capacitar. Ou 
seja, neste jogo o interesse individual pode-se contrapor ao interesse social, o que justifica uma ação do governo.

Neste cenário, propõe-se a intervenção do governo através do sistema previdenciário, atuando não apenas como garantidor do financiamento do período improdutivo, mas se abrindo a possibilidade de intermedição na relação firma-trabalhador. Para evitar esse prejuízo social, pode-se pensar em um mecanismo de renovação que procura por uma retirada eficiente do trabalhador veterano. A saída eficiente é determinada pela relação entre as produtividades do trabalhador veterano e do trabalhador reserva, e suas respectivas externalidades. A retirada precoce leva a uma perda produtiva, dada pela diferença entre a produtividade de um trabalhador que se encontra em um período de produtividade decrescente, mas ainda alta, e a produtividade daquele que assumiu a vaga. Por outro lado, a retirada tardia do trabalhador também representa uma perda por retardar a entrada de um trabalhador mais produtivo que poderia assumir esta vaga.

Os ganhos com a entrada de um trabalhador mais produtivo permite repassar ao trabalhador veterano uma compensação por uma antecipação em sua saída, na forma de benefício previdenciário. De forma semelhante, os ganhos obtidos pela postergação na saída de um trabalhador com intenções de se retirar precocemente são capazes de suprir a maior desutilidade enfrentada pelo mesmo. Desta forma, há uma melhoria onde trabalhador e mercado se beneficiam, levando a melhorias do tipo pareto ótimo. Agrega-se aos objetivos previdenciários estes ganhos potenciais de eficiência, que implicam em ganhos sociais. O ganho potencial, é obtido pela diferença entre o ganho sobre o trabalhador veterano e o que seria ganho caso este cedesse lugar ao trabalhador reserva.

Denota-se $T_{R}$ como o tempo de retirada eficiente para o mercado de trabalho, dado por

$$
\frac{\partial \pi\left(T_{R}\right)}{\partial t}=\frac{\partial \pi_{R}\left(T_{R}\right)}{\partial t}
$$

onde $\pi(t)$ e $\pi_{R}(t)$ são, respectivamente, o ganho acumulado sobre o trabalhador veterano e sobre o trabalhador reserva. Além das produtividades, são incorporados nestes ganhos, as externalidades geradas pela entrada ou permanência de um trabalhador. De forma a enriquecer a análise, considerase, $T_{A}<T_{R}<T_{B}$.

Inicialmente, analisa-se a atuação previdenciária sob informação perfeita das características dos trabalhadores no momento de finalizar o contrato. Faz-se uso da contribuição por unidade de tempo encontrada na seção anterior, $p=p^{*}$, sendo esta a contribuição que promove o equilíbrio nas contas previdenciárias dadas as condições e decisões anteriores (Equação 9).

A nova função objetivo do governo é maximizada através da escolha de $t$, diferentemente de antes quando a retirada era dada pelo próprio trabalhador, contudo, não se controla esta variável diretamente. Esta maximização ocorre por mudanças em $b(t)$, influenciando o trabalhador para um maior ou menor tempo trabalhado.

O novo contrato é dado por $b^{*}(T)+\Delta b(t, T)$, onde a primeira parcela é dada pela equação 7 e a segunda determinada com base nos interesses de promover eficiência para o mercado de trabalho. A função objetivo do governo neste momento é descrita por:

$$
\begin{array}{r}
\max _{t_{A}, t_{B}, \Delta b} V(t)=\sum^{N} \lambda\left\{\Pi\left(t_{A}\right)+\Delta p\left(t_{A}, T_{A}\right)-\Delta b\left(t_{A}, T_{A}\right)\right\}(1-\lambda) \\
\left\{\Pi\left(t_{B}\right)+\Delta p\left(t_{B}, T_{B}\right)-\Delta b\left(t_{B}, T_{B}\right)\right\}
\end{array}
$$

sujeito a:

$$
\begin{aligned}
\Delta b\left(t_{A}, T_{A}\right) & \geq \Delta \theta\left(d_{A}, t_{A}, T_{A}\right)-\overbrace{\Delta c\left(t_{A}, T_{A}\right)}^{\Delta w\left(t_{A}, T_{A}\right)-\Delta p_{\alpha}\left(t_{A}, T_{A}\right)} \\
\Delta b\left(t_{B}, T_{B}\right) & \geq \Delta \theta\left(d_{B}, t_{B}, T_{B}\right)-\Delta c\left(t_{B}, T_{B}\right)
\end{aligned}
$$


A busca pelo equilíbrio financeiro deixa lugar a uma busca pela maximização dos ganhos de eficiência no mercado de trabalho. Este ganho, representado por $\Pi(t)$, é função do ganho acumulado sobre o trabalhador veterano, da data natural de saída, $T$, ate sua saída efetiva, em $t$, comparado ao que teria sido ganho pelo trabalhador reserva neste mesmo período, ou seja, $\Pi\left(\Delta \pi\left(t, T_{A}\right), \Delta \pi_{R}\left(t, T_{A}\right)\right)$. $\Pi(t)$ é uma função côncava em relação a $t$, tendo como ponto de máximo $t=T_{R}$, dado pela própria definição de $T_{R}$.

A possibilidade de $t \neq T_{A}$ ou $t \neq T_{B}$ promove um desequilíbrio nas contas previdenciárias, anteriormente preservado pela determinação de $p=p^{*}$. A função objetivo permite tais desajustes, desde que seja compensado por variações em $\Pi(t)$, ou seja, as externalidades da ação do sistema previdenciário serão consideradas como justificativas para o desequilíbrio financeiro.

A restrição apresentada na equação 15 tem por objetivo garantir que as modificações sobre beneficios não venham a prejudicar o objetivo fundamental do sistema previdenciário, anteriormente garantido pela definição de $p=p^{*}$. Observa-se que, definida a contribuição por unidade de tempo, passou-se a definir a renda disponível acumulada no período ativo como $c(t)=w(t)-p_{\alpha}(t)$, podendo ser denominada como consumo autofinanciado. A solução para este problema é dada simetricamente para ambos os trabalhadores, como:

$$
\begin{aligned}
& \Delta b^{*}\left(t_{A}, T_{A}\right)=\Delta \theta\left(d_{A}, t_{A}, T_{A}\right)-\Delta c\left(t_{A}, T_{A}\right) \\
& \Delta b^{*}\left(t_{B}, T_{B}\right)=\Delta \theta\left(d_{B}, t_{B}, T_{B}\right)-\Delta c\left(t_{B}, T_{B}\right)
\end{aligned}
$$

onde $t^{*}$ é determinado por:

$$
\begin{aligned}
& \Pi^{\prime}\left(t_{A}^{*}\right)+p^{\prime}\left(t_{A}^{*}\right)=\theta^{\prime}\left(d_{A}, t_{A}^{*}\right)-c^{\prime}\left(t_{A}^{*}\right) \\
& \Pi^{\prime}\left(t_{B}^{*}\right)+p^{\prime}\left(t_{B}^{*}\right)=\theta^{\prime}\left(d_{B}, t_{B}^{*}\right)-c^{\prime}\left(t_{B}^{*}\right)
\end{aligned}
$$

Observa-se que a variação no benefício, $\Delta b(t, T)$, promovida pela mudança na data de saída, de $T$ para $t$, deve compensar as variações na desutilidade de permanência, $\Delta \theta(d, t, T)$, e no consumo autofinanciado no período ativo, $\Delta c(t, T)$, ou seja, as variações nas datas de saída devem garantir a utilidade mínima anteriormente citada. o termo $\Delta \theta(d, t, T)$ representa a diferença da contrapartida social do trabalhador. Um valor positivo implica que o trabalhador está fornecendo ao mercado mais esforço do que pretendia, enquanto um valor negativo representa o inverso, o trabalhador deixa o mercado sem a contribuição mínima estipulada.

O tempo ótimo de retirada do trabalhador é definido quando a igualdade na variação marginal dos ganhos de eficiência e na arrecadação se igualam à variação marginal do benefício necessário para incentivar o trabalhador a alterar sua decisão. Por sua vez, esta variação do benefício é dada pela diferença entre a variação da desutilidade e do consumo autofinanciado. Portanto, $t$ é definido pelas variações marginais entre os ganhos sociais, $\Pi^{\prime}(t)+p^{\prime}(t)$, e as variações marginais dos custos individuais, $\theta^{\prime}(d, t)-c^{\prime}(t)$.

Para o trabalhador com alta disposição a se retirar, em $T_{A}$, a desutilidade marginal de permanecer no mercado é maior que a utilidade marginal do consumo autofinanciado, $\theta^{\prime}\left(d_{A}, T_{A}\right)>c^{\prime}\left(T_{A}\right) .{ }^{15}$ Dada a pressuposição de $T_{A}<T_{R}$, o benefício $b_{A}$ deverá ser maior, de forma a induzir um $t$ maior. $0 t$ desejado é aquele que proporcione um ganho marginal de produtividade e de arrecadação de contribuição capaz de remunerar o excedente da desutilidade proporcionado pela maior permanência. Este novo ponto estará entre $T_{A}$ e $T_{R}{ }^{16}$ (Figura 2.a).

Como $T_{B}>T_{R}$, o sistema previdenciário procura reduzir o tempo de permanência do trabalhador com baixa disposição a se retirar. Em $T_{B}, \theta^{\prime}\left(d_{B}, T_{B}\right)>c^{\prime}\left(T_{B}\right)$, portanto, a redução do tempo de

\footnotetext{
${ }^{15}$ Dada a definição de $T_{A}$ dada pela equação 4 . Em caso contrário, não haveria motivos para o interesse natural de se retirar neste tempo.

${ }^{16}$ Desde que $p^{\prime}(t)$ não seja grande o suficiente para se sobrepor à perda do trabalhador e do mercado após $T_{R}$, quando $\Pi^{\prime}(t)=0$
} 
Figura 2: Tempo ótimo de retirada do trabalhador

Gráfico: A

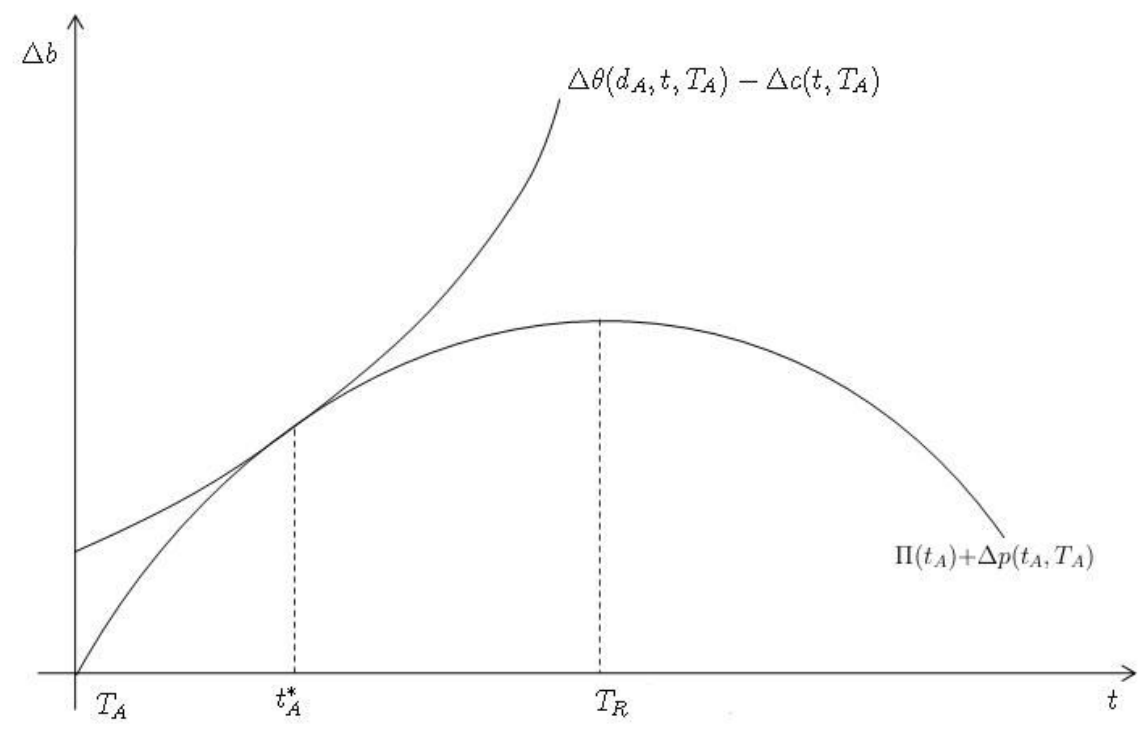

Gráfico: B

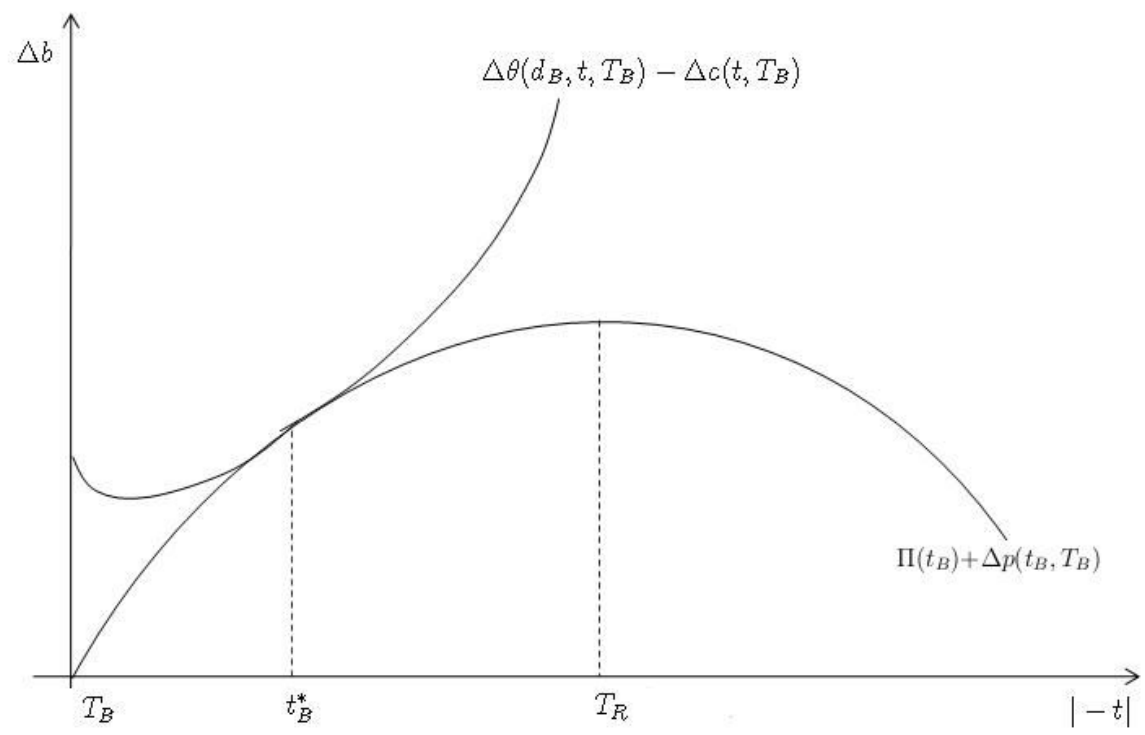


retirada promove a redução inicial do beneficio e o crescimento de produtividade no mercado. Em contrapartida, a arrecadação é reduzida em razão da redução no tempo de contribuição. Posteriormente, a redução de $t_{B}$, ao alcançar o ponto onde $\theta^{\prime}\left(d_{B}, t\right)=c^{\prime}(t)$, torna necessário o aumento no benefício, de forma a compensar o excesso da perda de consumo e consequente perda de utilidade. $t_{B}$ será determinado quando o ganho marginal do mercado se igualar à perda na arrecadação mais a variação necessária no benefício. (Figura 2.b)

Deve-se ressaltar que, da mesma forma que pode haver um déficit previdenciário compensado pelo ganho no mercado, também é possível haver um prejuízo no mercado contrabalanceado pelo crescimento da contribuição. Isto permitiria um superávit ou uma redução de um déficit pré-existente.

Proposição 3. O equilíbrio financeiro do sistema previdenciário, justificado por atuar como um seguro social, abre espaço para possíveis déficts quando se contabiliza as externalidades positivas sobre o mercado de trabalho. Por outro lado, a busca por um sistema superavitário teria repercussão negativa sobre a alocação eficiente da mão de obra.

Como anteriormente, quebra-se a pressuposição de informação completa sobre os trabalhadores no momento de finalizar o contrato. Com o uso do valor de $p=p^{* *}$, encontrado com base no problema descrito pela equação 11, a busca pela eficiência no mercado de trabalho terá que preservar os efeitos das restrições de compatibilidade de incentivos. O benefício dos trabalhadores com baixa disposição a se aposentar, tipo $d_{B}$, terá em seu valor, a inclusão do prêmio pela informação. Portanto, as variações nos benefícios deverão preservar as condições que levam o trabalhador a revelar seu tipo.

Por outro lado, o efeito mais interessante será sobre o tempo de permanência do trabalhador com alta disposição a se aposentar, tipo $d_{A}$. O adiamento da saída deste trabalhador terá uma influência sobre o pagamento do benefício do trabalhador com baixa disposição. Quanto mais tempo o tipo $d_{A}$ permanecer ativo, maior será o benefício pago ao mesmo, em contrapartida, mais atrativo será, para os trabalhadores com baixa disposição a sair, mentir sobre suas preferências para usufruir dos beneficios deste contrato. Portanto, os ganhos de manter um trabalhador de tipo $d_{A}$ teria que cobrir, além das perdas deste trabalhador pela maior permanência, a variação do valor do prêmio pela informação pago ao trabalhador com disposição $d_{B}$. Este aumento no custo de manter os trabalhadores de alta disposição promove aposentadorias mais precoces dos mesmos. Tais resultados podem ser observados na resolução apresentada abaixo.

$$
\begin{aligned}
& \Delta b^{* *}\left(t_{A}, T_{A}\right)=\Delta \theta\left(d_{A}, t_{A}, T_{A}\right)-\Delta c\left(t_{A}, T_{A}\right) \\
& \Delta b^{* *}\left(t_{B}, T_{B}\right)=\Delta \theta\left(d_{B}, t_{B}, T_{B}\right)-\Delta c\left(t_{B}, T_{B}\right)+\Delta \theta\left(d_{A}, t_{A}, T_{A}\right)-\Delta \theta\left(d_{B}, t_{A}, T_{A}\right)
\end{aligned}
$$

onde $t^{* *}$ é dado por:

$$
\begin{aligned}
\Pi^{\prime}\left(t_{A}\right)+p^{\prime}\left(t_{A}\right) & =\left[\theta^{\prime}\left(d_{A}, t_{A}\right)-c^{\prime}\left(t_{A}\right)\right]+\frac{(1-\lambda)}{\lambda}\left\{\left[\theta^{\prime}\left(d_{A}, t_{A}\right)-\theta^{\prime}\left(d_{B}, t_{A}\right)\right]\right\} \\
\Pi^{\prime}\left(t_{B}\right)+p^{\prime}\left(t_{B}\right) & =\left[\theta^{\prime}\left(d_{B}, t_{B}\right)-c^{\prime}\left(t_{B}\right)\right]
\end{aligned}
$$

O benefício do trabalhador do tipo $d_{A}$ irá variar de acordo com a diferença da variação na desutilidade e no consumo, ou seja, é igualmente recompensado no contrato com informação perfeita. Seu tempo de permanência no mercado, contudo, terá que compensar, não somente os custos pela maior permanência, mas também os ajustes sobre o valor do prêmio pela informação do trabalhador tipo $d_{B}$.

Na definição de $b\left(t_{B}\right)^{* *}$ foi pago um prêmio dado pela diferença entre $\theta\left(d_{B}, T_{B}\right)$ e $\theta\left(d_{B}, T_{A}\right)$ (equação 13). Com a mudança nas datas de saída, haverá um reajuste sobre este valor dado por: $\theta^{\prime}\left(d_{A}, t_{A}\right)-\theta^{\prime}\left(d_{B}, t_{A}\right) \cdot{ }^{17}$

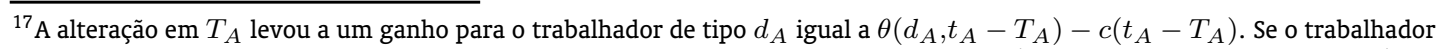
$d_{B}$ se passar pelo de alta disposição a se retirar, incorrerá em um ganho dado por $\left(\Delta \theta\left(d_{A}, t_{A}, T_{A}\right)-\Delta c\left(t_{A}, T_{A}\right)\right)-$ $\left(\Delta \theta\left(d_{B}, t_{A}, T_{A}\right)-\Delta c\left(t_{A}, T_{A}\right)\right)$.
} 
Por fim, o trabalhador $d_{B}$ receberá um benefício tão maior quanto a diferença entre as desutilidades dos trabalhadores que compõem a mão-de-obra do mercado, ou seja, quanto maior a proporção destes trabalhadores e maior essa diferença dos custos entre os trabalhadores mais custoso é a manutenção da atividade de um trabalhador com alta disposição a sair do mercado de trabalho, e consequentemente, menor será $t_{A}$.

Proposição 4. A existência de aposentadorias precoces pode estar ligado à formulação de contratos socialmente eficientes.

Sob a suposição de informação incompletas quanto às preferências dos trabalhadores, adiar a saída do trabalhador com alta disposição a sair fica mais custoso quanto mais divergirem os custos oportunidades dos trabalhadores quanto a permancerem na atividade, e quanto maior for o percentual de trabalhadores com baixa disposição a sair em relação aos de alta disposição. Portanto, tal pressuposição colabora para uma retirada mais precoce de alguns trabalhadores do que aquela que ocorreria caso houvesse perfeita informação sobre as preferências.

\subsection{Implicação do Modelo}

A estrutura deste jogo permite analisar o sistema previdenciário de acordo com suas funções sociais. A utilização deste sistema como um instrumento para promoção de bem estar social, ao focar resultados outros que não a formação da poupança de longo prazo aos trabalhadores, tem consequências e custos que muitas vezes não são considerados. 0 desequilíbrio nas contas previdenciárias são sempre ligados há um sistema ineficiente, pois o foco das discussões se restringem, muitas vezes, a contabilizar a justiça atuarial individual, onde um pagamento de benefício previdenciário a um determinado trabalhador, deve-se ater aos níveis de contribuição feitos pelo mesmo.

O que o modelo destaca são as externalidades geradas sobre a sociedade, mais especificamente sobre o mercado de trabalho. A existência do sistema previdenciário, apenas como garantidor da poupança para a inatividade, já apresenta interferências no livre mercado, fato que impede o sistema social de se aproximar de um sistema de capitalização, onde contribuição é estritamente ligada ao valor do beneficio. Ou seja, o sistema previdenciário ao se comprometer com a promoção da poupança de longo prazo, necessária ao financiamento do período inativo do trabalhador, pode criar imperfeições na economia dada sua influência na decisão de saída. Neste caso, os trabalhadores passam a oferecer ao mercado mais ou menos tempo do que pretendiam, e isto implica em prejuízos ao trabalhador (devido à maior desutilidade despendida), ou ao mercado (devido ao menor aproveitamento da capacidade do trabalhador).

Soma-se a esta interferência inerente do sistema sobre a sociedade, a tentativa do governo em conduzir as externalidades em prol de ganhos de eficiência na alocação da mão de obra produtiva. Baseado em divergência entre interesse individual, das firmas e dos trabalhadores, e o interesse social de uso eficiente da capacidade produtiva, o governo passa a aceitar desequilíbrios financeiros, como custos sociais para a correção de falhas do mercado de trabalho.

Na determinação dos benefícios da subseção 3.1.2, observa-se um financiamento cruzado dos benefícios entre os trabalhadores, definidos pelo nível de assimetria de informação e pela própria configuração da população em questão. A existência de transferência intrageracional se faz necessária a partir do momento em que há dificuldades para distinção entre os indivíduos na sociedade, seja no momento de recolher as contribuições ou no pagamento dos benefícios.

Observou-se, também, que quanto maior a desinformação sobre as preferências dos trabalhadores, maiores são os custos deste sistema, ou maior a interferência sobre as decisões naturais. E quanto maior é a desigualdade da população relacionada às disposições a se aposentar, maiores serão os custos e menor será a capacidade de melhoras na alocação do mercado de trabalho.

As preferências do trabalhador quanto a decisão de se aposentar é dependente de diversos fatores, e cada trabalhador irá lidar com estes de forma diferente, baseado em culturas e instituições às quais foi 
exposto. A literatura consultada permite apontar alguns pontos determinantes entre os trabalhadores no momento de decisão, como família, saúde, renda, idade, dentre outros.

Dada a inconstitucionalidade de discriminar os trabalhadores no sistema de previdência social, além de tal processo poder ser muito complexo trazendo insegurança e confusão para a sociedade, pode-se captar o tamanho das diversidades destes fatores na socidade o que permite a elaboração de um menu de contratos de incentivos, onde o próprio trabalhador revelaria suas preferências. Ressalta-se novamente, que os custos de manutenção de um sistema socialmente justo e a capacidade de melhorias na alocação eficiente da mão de obra no mercado de trabalho, sob informação assimétrica, estão diretamente ligados às configurações da população e em como tais configurações são de conhecimento dos elaboradores dos contratos.

Sob esta ótica de buscar os resultados gerados pelas externalidades, assegurando o cumprimento de seu objetivo fundamental de promover a poupança para a inatividade, a redução do déficit previdenciário, que diversas vezes é colocada como principal argumento em reformas que propõem a postergação das saídas dos trabalhadores, pode acobertar um prejuízo maior para o mercado, como apresentado na determinação da saída ótima do trabalhador na subseção 3.1.3.

Portanto, a questão das contas do sistema previdenciário não deve se submeter ao questionamento da existência ou não de um déficit, mas de como é custeada e qual a contrapartida deste para o bemestar social.

\section{CONCLUSÕES}

A literatura referente ao estudo dos sistemas previdenciários possui como enfoque principal, a evolução dos déficits, a justiça atuarial e o efeito sobre a poupança agregada, que são vistos como a essência da atuação previdenciária.

Este trabalho buscou a base para a construção de um sistema mais eficiente e eficaz com base nos fundamentos microeconômicos. A análise se restringiu à abordagem teórica da decisão de saída do trabalhador de forma a relacioná-la aos interesses sociais.

Este trabalho também veio a contribuir na formalização deste mecanismo de interferência da previdência através de um modelo de Principal-Agente. Este se mostrou viável para analisar e indicar caminhos na solução de conflitos de interesses entre as preferências dos trabalhadores e necessidades no mercado de trabalho. Com base na teoria dos incentivos, mostrou-se como as regras previdenciárias podem gerar efeitos danosos ou benéficos sobre a economia através da interferência na decisão de retirada do trabalhador. Efeito também previsto em trabalhos como em (Bhattacharya et alii, 2004, Cooley, 1999, Gruber e Wise, 1998, Sala-I-Martin, 1996).

Em suma, o modelo destaca o potencial do sistema previdenciário na renovação da mão-de-obra no mercado de trabalho. As regras previdenciárias elaboradas de forma a incorporar a identidade dos indivíduos permitem ganhos para a economia pela influência na produtividade da produção. Quanto maiores as diferenças entre as preferências da permanência no mercado entre os trabalhadores, maior a necessidade de que o sistema procure diferenciá-los.

Destacou-se, ainda, que não apenas problemas de desequilíbrios financeiros devem ser observados na previdência social, pois reformas visando apenas a redução destes podem promover prejuízos para o mercado na forma de custos sociais. Cria-se então a possibilidade da sociedade arcar com um déficit previdenciário, desde que este seja utilizado para promoção de maior bem estar social.

O objetivo intrínseco, deste trabalho, de incentivar a discussão quanto ao papel do sistema previdenciário na sociedade, abre espaço para discussões outras como a eficiência do sistema no fomento do bem estar social, seja sobre o mercado de trabalho ou atuando sobre outros objetivos.

Em razão da grandiosa cobertura sobre a sociedade e os volumosos fluxos monetários controlados pelo sistema, cada vez mais a previdência social agrega responsabilidades e novos objetivos. Podese citar: a redistribuição de renda, o assistencialismo, a influência no nível de poupança agregada 
e, como foco deste trabalho, a permanência da mão-de-obra produtiva no mercado (Coimbra, 2011). Tais objetivos complementares ao sistema previdenciário justificariam maiores déficits financiados pela sociedade, contudo, o sistema previdenciário pode não se apresentar como ferramenta mais eficiente na execução destas propostas. Ou seja, será o sistema previdenciário a melhor ferramenta para intervenção do governo visando cada um destes objetivos?

Por fim, recomenda-se maiores investigações quanto à divisão do financiamento do sistema previdenciário entre trabalhador, firma e sociedade. Pode-se questionar os ganhos sociais pela intervenção do governo como apresentado no modelo, contraposto aos ganhos privados das empresas, assim como quais outros interesses e responsabilidades cada financiador detém sobre o sistema.

\section{BIBLIOGRAFIA}

Ando, A. \& Mondigliani, F. (1963). The "life cycle" hypothesis of saving: Aggregate implications and tests. The American Economic Review, 53:55-84.

Bhattacharya, J., Mulligan, C. B., \& Reed, R. R. (2004). Labor market search and optimal retirement policy. Economic Inquiry, 42:560-571.

Coimbra, L. W. P. (2011). Mecanismo de incentivo a renovação da mão-de-obra no mercado de trabalho face ao sistema previdenciário. Dissertação (mestrado), Universidade Federal de Pernambuco, Recife.

Conde-Ruiz, J. I. \& Galasso, V. (2003). Early retirement. Review of Economic Dynamics, 6(1):12-36.

Cooley, T. F. (1999). A positive theory of social security based on reputation. Journal of Political Economy, 107(1):135-160.

Ferreira, S. G. (2007). Sistemas previdenciários no mundo: Sem "almoço grátis". In Tafner, P. \& Giambiagi, F., editors, Previdência no Brasil: Debates, dilemas e escolhas, pages 65-93. IPEA, Rio de Janeiro.

Gruber, J. \& Wise, D. (1998). Social security and retirement: An international comparison. American Economic Review, 88(2):158-163.

Gustman, A. L. \& Steinmeier, T. L. (1986). A structural retirement model. Econometrica, 54:555-584.

Izerrougene, B. (2009). A macroeconomia da previdência social. Revista de Economia Contemporânea, 13(1):31-45.

Kotlikoff, L. \& Gokhale, J. (1992). Estimating a firm's age-productivity profile using the present value of worker's earnings. Quarterly Journal of Economics, pages 1215-1242.

Lazear, E. (1987). Retirement from the labor force. In Ashenfelter, O. \& Layard, R., editors, Handbook of Labor Economics, pages 305-355. Elsevier.

Lazear, E. P. (1979). Why is there mandatory retirement? Journal of Political Economy, 87(6):1261-1284.

Leme, M. C. S. \& Málaga, T. (2001). Entrada e saída precoce da força de trabalho: Incentivos de previdência brasileiro. Revista Brasileira de Economia, 55(2):205-222.

Liberato, V. C. (2003). A oferta de trabalho masculina "pós-aposentadoria" Brasil urbano - 1981/2001. Dissertação de mestrado, Universidade Federal de Minas Gerais - UFMG, Belo Horizonte.

Mete, C. \& Schultz, T. P. (2002). Health and labor force participation of the elderly in Taiwan. Center Discussion Paper, Yale University: New Haven. n.846. http ://ideas. repec . org/p/egc/wpaper/ 846.html. Acesso em: 28 set. 2012. 
Mitchell, O. \& Fields, G. (1984). The economics of retirement behavior. Journal of Labor Economics, 1(2):84-105.

MPAS (2011). Anuário Estatístico da Previdência Social. Anuário estatístico, Ministério da Previdência e Assistência Social.

Perez, E. R., Wajnman, S., \& Oliveira, A. M. H. C. d. (2006). Análise dos determinantes da participação no mercado de trabalho dos idosos em São Paulo. Revista Brasileira de Estudos da população, 23:269-283.

Queiroz, B. L. (2008). Labor force participation and retirement behavior in Brazil. VDM Verlag Dr. Muller, Saarbrucken.

Sala-I-Martin, X. X. (1996). A positive theory of social security. Journal of Economic Growth, 1(2):277-304.

Tabellini, G. (2000). A positive theory of social security. Scandinavian Journal of Economics, 102(3):523545.

Tafner, P. (2007). Seguridade e previdência: Conceitos fundamentais. In Tafner, P. \& Giambiagi, F., editors, Previdência no Brasil: Debates, dilemas e escolhas, pages 29-63. IPEA, Rio de Janeiro. 